the evaporation per unit of area of heating surface and per unit of weight of fuel, as well as the measurement of the relative amount of smoke produced.

"The measurement of the amount of smoke produced by each device was accomplished by an ingenious method, which, while r robably hardly entitled to be considered as a method of precision, was still reasonably correct, and doubtless fair to all the devices tested.

" A smoke scale of five degrees of intensity, ranging from complete absence (of smoke) to complete opacity, was decided upon, and the amount produced was recorded upon cylinders revolved by clockwork, by means of a pencil which could be pressed into contact with the paper by hand. The observer, watching the chimney top, pressed the pencil against the paper during any period when smoke was produced, the paper being divided into five portions corresponding to the five grades of smoke."

So much for the method of the tests. The conclusions, which are of general applicability to all cities where the smoke problem is a live question, will be read with interest :

"In the first place, the experiments made before any of the special devices were tried, showed that the ordinary grate is unsuited for smokeless combustion, and that, even with the most careful stoking, the common grate wil1 permit the formation of smoke.

"In the second place, it was clearly demonstrated that smoke prevention and economy do not necessarily go together. The blackest of smoke represents an insignificant amount of fuel, and the tests demonstrated that the devices which produced the least smoke were not the most economical. It should, therefore, always be asiumed that the prevention of smoke involves expense, proper allowance being made therefor.

"Smoke may always be prevented by using coke, but as this is in many cases unavailable, the only remedy lies in the use of such devices as will produce a minimum of smoke, the true principle being, not the combustion of smoke, but the absence of its production.

"The commission recommeuded the prohibition of dense black smoke, as the trials showed that many devices would accomplish this result. It was also recommended that those devices which showed the best results during the tests-be placed in manufacturing establishments with the view of establishing their durability and effectiveness in regular service, and, above all, that the existing regulations be thoroughly enforced by patient and competent officials."

\title{
RENDERING CALCIUM CARBIDE STABLE IN THE AIR.
}

Calcium carbide, as is well-known, rapidly disintegrates when exposed to the air, through the action of the moisture therein contained; hence, it is necessary to preserve it in hermetically-sealed vessels until it is required for use.

In a recent English patent, the inventor proposes to obviate this difficulty by "saturating the carbide with liquid hydro-carbons, as for instance, petroleum." By this process, the carbide, immediately after the usual crushing operation, as it comes from the furnace, and which, still at a temperature of $212^{\circ}$ to $250^{\circ} \mathrm{F}$, is conveyed to a bath of petroleum residues, where it remains 
about five or ten minutes. It is then withdrawn and allowed to drain. When thus treated, it is said that the carbide is not affected by atmospheric moisture, whereas with a body of water it decomposes very* slowly at first, but with increasing rapidity "as the particles are laid bare."

W.

\section{ARTIFICIAL AND NATURAL INDIGO.}

The commercial production of artificial indigo by the Badische Anilin $\mathbf{u}$. Soda Fabrik, has aroused the greatest interest in the textile world, and has caused much attention to be devoted by chemists to the composition and properties of the natural product.

It has been shown that natural indigo constantly contains, besides indigotin and mineral matters, indirubin, indigo.brown, and indigo-gluten.

As the synthetical indigo is pure indigotin, it is a matter of some importance to determine whether the other incidental constituents of the natural product possess properties of value in dyeing, in order to ascertain the comparative value of the two products.

The results of the exhaustive study of the natural proluct by MM. Schwarzenberg and Schwartz appear to establish the following facts of value.

(I) The greater part of the indigo-gluten passes into solution in the indigo vat; a small quantity remains in the vat-sediment. This constituent of the natural product is without influence in dyeing.

(2) Indigo-brown forms an insoluble compound with lime and remains in the sediment. This constituent, also, has no effect on indigo dyeing.

(3) Indirubin dyes, to some extent, but it increases neither the fastness nor the brilliancy of shade of the dye; the effect, indeed, of a large pro. portion of it, is to give a shade which is dull and unpleasing.

These conclusions, it is stated, have recently been fully confirmed by the Badische Anilin u. Soda Fabrik. These manufacturers declare, also, that the fastness to rubbing and washing of their new artificial indigotin, when dyed on cotton fabrics in the ordinary manner, is equal if not slightly superior, to that of natural indigo. They state, also, that the shade and fastness of indigo $\mathrm{dy}$ es are not influenced by indirubin, indigo-gluten, and other organic substances present in indigo, but that such modifications as may occur in these features are due to methods of setting and working the vats.

It will be of interest to notice, in conclusion, that the manufacturers above-named, state that they are in a position to produce, by a synthetical process, indirubin.

W.

\section{DAMAGE TO IRON VESSELS BY GALVANIC ACTION AT A}

\section{DISTANCE.}

An unusual and interesting case of galvanic action exerted at a distance is reported from an Italian source. .

The captain of the port of Leghorn brought action in court against the owners of certain wooden yachts with coppered bottoms to compel them to remove their vessels from the neighborhood of a number of new war.ships and other vessels with iron or steel hulls lying in the same part of the harbor. 